\title{
Retraction Note: The abnormal precipitation in rainy season based on genetic algorithm and the security of big data in network
}

\author{
Haiyan $\mathrm{Fu}^{1}$
}

Published online: 17 November 2021

C) Saudi Society for Geosciences 2021

Retraction Note: Arabian Journal of Geosciences (2021) 14: 1592

https://doi.org/10.1007/s12517-021-07927-1

The Editor-in-Chief and the Publisher have retracted this article because the content of this article is nonsensical. The peer review process was not carried out in accordance with the Publisher's peer review policy. The author has not responded to correspondence regarding this retraction.

The original article can be found online at https://doi.org/10.1007/ s12517-021-07927-1.

Haiyan Fu

hnnfhy@163.com

1 School of Information Science and Technology, Hainan Normal University, Haikou 571158, China 